\title{
Gender differences in healthy life years within the EU: an exploration of the "health-survival" paradox
}

\author{
Herman Van Oyen • Wilma Nusselder • Carol Jagger • Petra Kolip • \\ Emmanuelle Cambois · Jean-Marie Robine
}

Received: 15 July 2011 / Revised: 26 February 2012 / Accepted: 16 April 2012 / Published online: 22 May 2012

(C) The Author(s) 2012. This article is published with open access at Springerlink.com

\begin{abstract}
Objectives To evaluated the female-male health-survival paradox by estimating the contribution of women's mortality advantage versus women's disability disadvantage.

Methods Disability prevalence was measured from the 2006 Survey on Income and Living Conditions in 25 European countries. Disability prevalence was applied to life tables to estimate healthy life years (HLY) at age 15. Gender differences in HLY were split into two parts: that due to gender inequality in mortality and that due to gender inequality in disability. The relationship between women's mortality advantage or disability disadvantage and the level of population health between countries was analysed using random-effects meta-regression.

Results Women's mortality advantage contributes to more HLY in women; women's higher prevalence of
\end{abstract}

H. Van Oyen $(\bowtie)$

Directorate of Public Health and Surveillance,

Scientific Institute of Public Health, J. Wytsmanstraat 14, 1050 Brussels, Belgium

e-mail: herman.vanoyen@wiv-isp.be; hvanoyen@wiv-isp.be

W. Nusselder

Erasmus MC, University Medical Center Rotterdam,

Rotterdam, The Netherlands

C. Jagger

Newcastle University, Newcastle, UK

P. Kolip

University of Bielefeld, Bielefeld, Germany

E. Cambois

French Institute for Demographic Studies, INED, Paris, France

J.-M. Robine

French Institute of Health and Medical Research, INSERM,

Montpellier, France disability reduces the difference in HLY. In populations with high life expectancy women's advantage in HLY was small or even a men's advantage was found. In populations with lower life expectancy, the hardship among men is already evident at young ages.

Conclusions The results suggest that the health-survival paradox is a function of the level of population health, dependent on modifiable factors.

Keywords Europe - Gender - Health expectancy · Health inequality · Healthy life years .

Health-survival paradox

\section{Introduction}

Life expectancy in women is higher than in men. Although women live longer in nearly all countries of the world (Barford et al. 2006) the gender gap in life expectancy has narrowed during the last decades of the twentieth century in most but not all European countries (Van Oyen et al. 2010). Though several biological hypotheses have been proposed (Austad 2006), the dynamics of the gender differences in mortality suggest that its determinants cannot be purely biological, but are also dependent on modifiable psycho-social and lifestyle factors (Barford et al. 2006; Gjonça et al. 2005). In developed countries smoking has been considered as one of the main causes of the gender difference in mortality (Jacobsen et al. 2008; Leon 2011; Pampel 2003; Payne 2004; Preston and Wang 2006). Within Europe, smoking accounts for 40-60\% of the mortality difference by gender, while alcohol contributes to 10-30\% of the gender gap (McCartney et al. 2011).

In many countries the mortality advantage of women is balanced by a disability disadvantage (Case and Paxson 
2005). This contrast is called the female-male healthsurvival paradox (Oksuzyan et al. 2008). The proposed explanations for the health-survival paradox are rooted in biological, social, and psychological interpretations (Oksuzyan et al. 2008). Although selection and information bias from gender differences in participation in surveys and reporting cannot be excluded, the contribution of both biases to the health-survival paradox is considered to be small (Oksuzyan et al. 2009).

To better understand the dynamics of population health and especially, the female-male health-survival paradox, the use of composite health indicators, such as health expectancies, has been proposed (Nusselder et al. 2010b). Health expectancies are summary measures of population health bringing together data on both the quantity and the quality of life (Robine 2006). They are considered to be important population health outcome measures (Stiefel et al. 2010). Health expectancies, predominantly disabilityfree life expectancy (DFLE), are available for many countries worldwide (Robine et al. 2003). Within the European Union, it was decided to estimate DFLE based on a measure of long-term activity limitations (Van Oyen et al. 2006), the healthy life years (HLY). Similar to life expectancy, HLY at a given age corresponds to the average life span free of activity limitation. The average life span with activity limitation is called unhealthy life years (ULY).

Gender difference in both HLY and ULY, can be split into two components: (1) the difference due to inequality in age-specific mortality rates ("mortality effect": gender difference in life expectancy without or with activity limitations due to differential mortality); and (2) difference due to gender inequality in age-specific prevalence of activity limitations ("disability effect": difference in life expectancy without or with activity limitations because of differences in the prevalence of activity limitations).

The current paper aims to better understand the healthsurvival paradox within the EU by examining the contribution of women's mortality advantage versus the disability disadvantage, and their differences between countries with better and worse population health. More specifically, we explore the following questions:

1. Does the mortality advantage and/or disability disadvantage of women vary between countries with high versus low life expectancy? We expect that in populations with high life expectancy, the gender gap in HLY is smaller because of a combination of a smaller mortality advantage and a larger disability disadvantage in females.

2. Is there a shift in the concentration of the mortality and disability effects on the gender gap in HLY towards older age groups (50 years and above) when indicators of population health (e.g., having a longer life, a longer life without activity limitations or a shorter life with activity limitations) are improving? We hypothesize that in countries with better scores on the population health indicators, the effects of both mortality and disability on the gender gap in HLY is more concentrated in older age groups.

The added value of the paper is to study the healthsurvival paradox through HLY, which combines both health and survival.

\section{Methods}

Data

We used EU member states specific data of the European Health Expectancy Monitoring Unit Information System (http://www.ehemu.eu): age and sex-specific data on (1) number of deaths (2006); (2) population (2006, 2007); and (3) prevalence of activity limitations (number of persons with activity limitations and the total number in the sample) from the 2006 Statistics of Living and Income Survey (SILC). The SILC is an EU-wide survey, initiated in 2005. A description of the survey can be found in "http:// circa.europa.eu/public/irc/dsis/eusilc.library". The SILC survey population consists of nationally representative probabilistic samples from community dwelling populations. The 2006 SILC survey covers a total of 375,243 participants of age 16 years and above. Overall response rate averaged over countries is about $20 \%$ but with large between countries variations (from $95 \%$ in Cyprus to $60 \%$ in Denmark and Belgium) (Eurostat 2009).

\section{Activity limitations}

The SILC contains the Minimum European Health Module (Robine and Jagger 2003), which includes a disability measure, the global activity limitation indicator (GALI). The GALI ("For at least the last 6 months, have you been limited because of a health problem in activities people usually do?") aims to capture long-term limitation in usual activities, caused by ill-health (Van Oyen et al. 2006) and provides the health status information to calculate HLY. The validity and the reliability of the GALI have been documented (Cox et al. 2009; Jagger et al. 2010; Van Oyen et al. 2006).

Statistical methods

HLY at age 15 was calculated using the Sullivan method, which integrates age-specific disability prevalence into the 
life table (Jagger et al. 2007; Sullivan 1971). ULY are calculated as the difference between life expectancy (LE) and HLY.

To estimate the contribution of the mortality and disability effects to the gender differences (females - males) in HLY and ULY, a decomposition methodology was used (Nusselder et al. 2005; Nusselder and Looman 2004). This method is an extension of the decomposition techniques used in mortality research (Arriaga 1984) to assess the contribution of age or specific diseases to differences in LE. Gender inequalities in LE reflect differences in mortality rates only. Gender differences in HLY or ULY are a result of differences in mortality combined with differences in the prevalence of activity limitations. The decomposition method allows the estimation of the percentage of mortality or disability effects of the gender difference in HLY (or in ULY) that are due to differences in specific age groups (e.g., younger ages (15-49 years) or older ages $(50+$ years)). Calculations were done using R. A statistical description of the decomposition methods including a manual for the R-macro has been described http://www. eurohex.eu/pdf/Reports_2010/2010TR7.1_Decomposition \%20tools.pdf (Nusselder et al. 2010a). The variance and $95 \% \mathrm{CI}$ around the mortality and disability effects were estimated by a bootstrap procedure with 1,000 resamples (Efron and Tibshirani 1993) with the assumption that the number of age-specific deaths followed a Poisson distribution, and the number of persons with activity limitations resampled within the sample size of the age-specific survey groups followed a binomial distribution. The 2.5 and 97.5 percentile of the bootstrap distribution defined the $95 \%$ CI boundaries.

To evaluate the health-survival paradox we investigate the relationship between the mortality advantage or the disability disadvantage that women experience over men and the duration and/or the gender gap in the duration of total, healthy or unhealthy life using random-effects metaregression models in STATA-10 (Sutton and Abrams 2001). In contrast to ordinary regression models, these models account for the uncertainty around the countryspecific mortality or disability effect.

We use three univariable models (model Type 1) each assessing the relationship of the mortality effect of the gender difference in HLY (dependent variable) with an independent variable representing the overall length of life (women's LE, men's LE and gender difference in LE). Model Type 2 is multivariable, adjusting the gender difference in LE for women's LE to account for the association between gender difference in LE and longer life (Van Oyen et al. 2010). A similar modelling process (Type 1 and Type 2) is adopted for assessing the relationship between the mortality effect of the gender difference in HLY and overall HLY (women's HLY, men's HLY and gender difference in HLY) and then overall ULY. Finally, the whole is repeated for assessing (1) the relationship of the disability effect of the gender difference in HLY with the overall length of life, of healthy life and of unhealthy life and (2) the relationship of the mortality or disability effect of the gender difference in ULY with the overall length of life, of healthy life and of unhealthy life. We present the univariable associations by line graphs of the fitted values, with the estimates from each member state represented by circles, the circle sizes depending on the precision of each estimate (the inverse of its within-country variance), which is the weight given to each country in the model. Similar models were used when the dependent variable was the relative contribution (\%) of older age (50+ years) to the mortality and disability effect of the gender difference in HLY or in ULY.

\section{Results}

Tables 1 and 2 provide the estimates of the different health expectancy indicators, the gender differences (female male) and the decomposition by type of effect at age 15 years. Data are summarized by boxplots (Fig. 1). Women's LE at age 15 years always exceeds male LE, but LE varies substantially across countries as does the gender difference which varies from 3.5 to 11.6 years.

The median gender difference in HLY (0.8 years) is less than that for LE (5.6 years). The variation in the gender difference in HLY [interquartile range (IQR): 2.4, range: 6.2] is also smaller than that for LE (IQR: 3.2, range: 8.2). In 7 countries (Cyprus, Denmark, Germany, Italy, the Netherlands, Portugal and Spain), men at age 15 can expect to live more years without activity limitations than women, the gender difference in HLY reaching statistical significance in 3 of these countries (Cyprus, the Netherlands and Portugal). In all countries, women live more years with activity limitations than men, the median gender difference in ULY being 5.4 years (IQR 2.8, range 5.8).

\section{Decomposition of the gender difference in HLY}

The gender difference is HLY is the sum of two opposing forces. Women's mortality advantage increases the HLY gender difference, while women's disability disadvantage reduces the HLY gender difference. In all countries, the value of the mortality effect is positive (Table 2) meaning that women's mortality advantage over men contributes to more HLY in women. On average this amounts to $2.8 \mathrm{HLY}$ (IQR 1.04, range 3.6 years) with the highest value (5.3 years) in Lithuania as an outlier (Fig. 1). In all but two countries (Austria and Estonia), the disability effect on HLY is negative, meaning that the higher prevalence of 


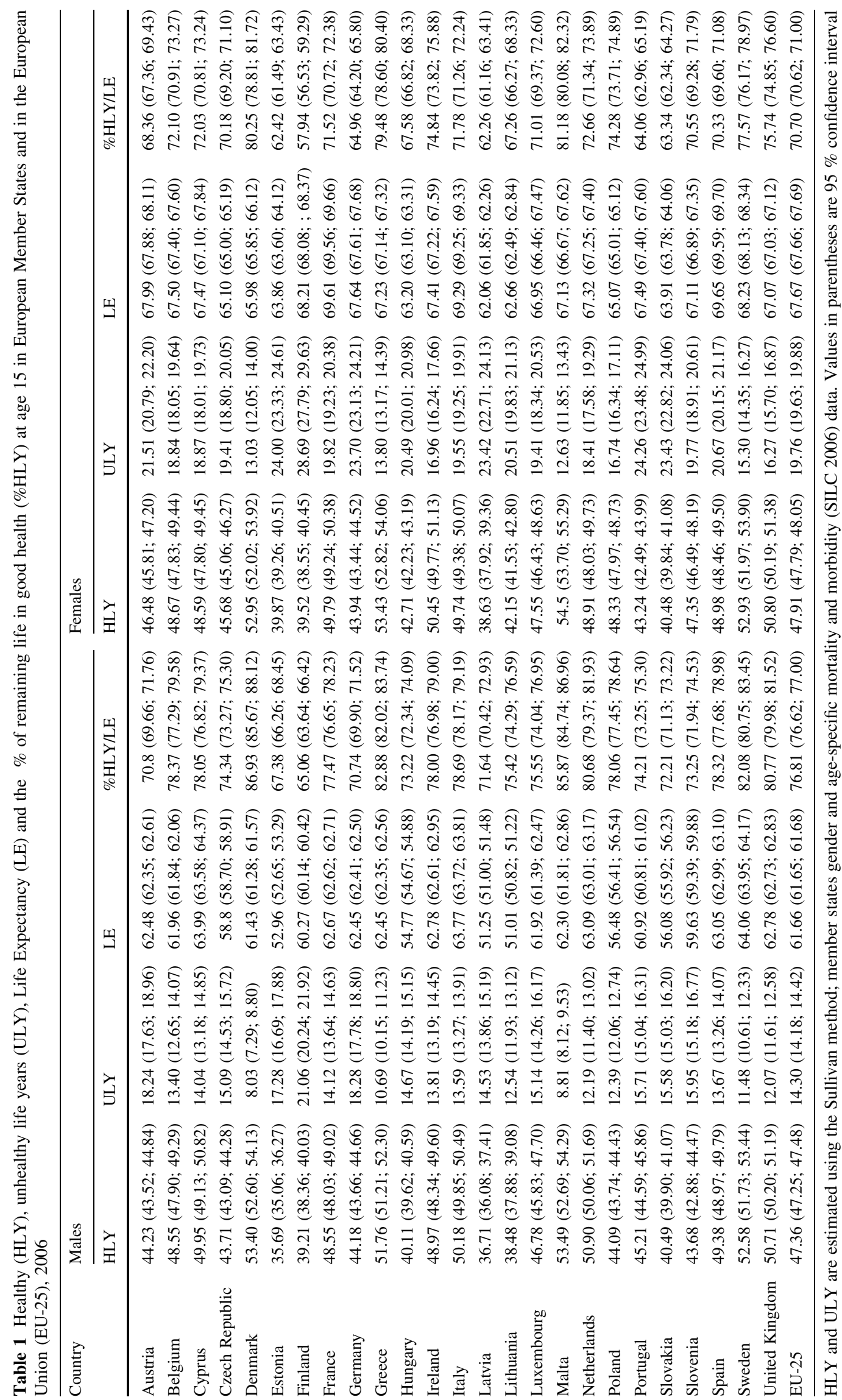




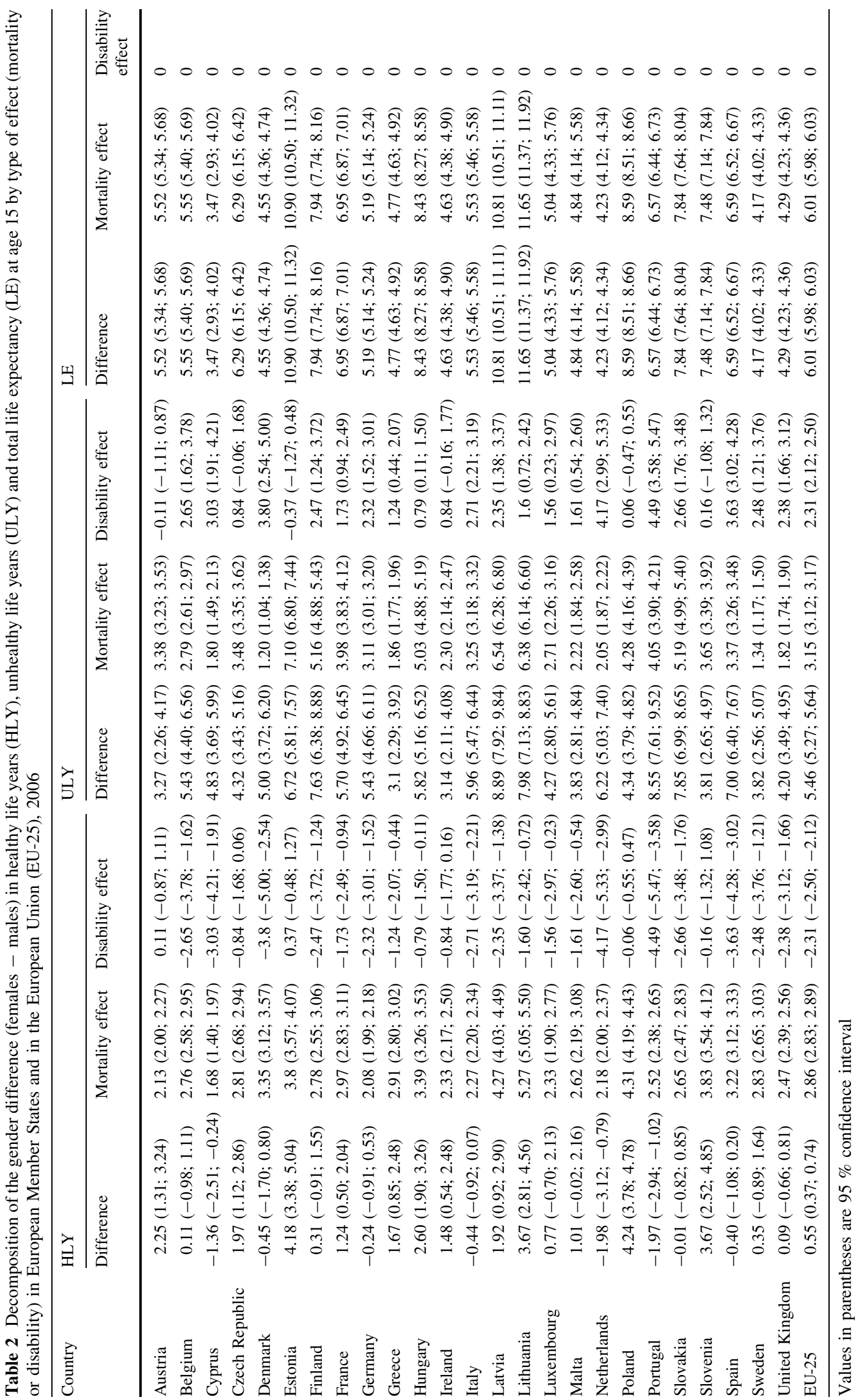




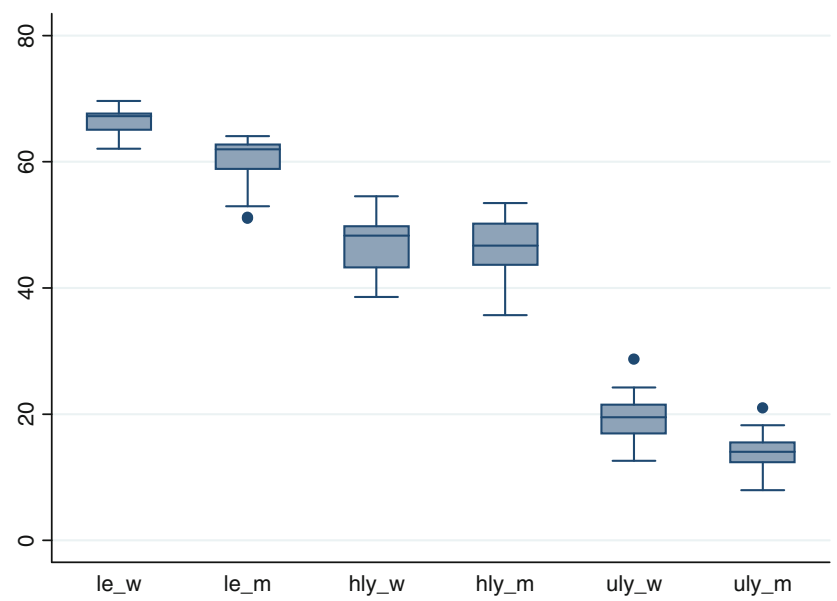

*: $\mathrm{m}=$ males, $\mathrm{w}=$ women

le_m, le_w: life expectancy men, women

hly_m, hly_w: healthy life years men, women

uly_m, uly_w: unhealthy life years men, women

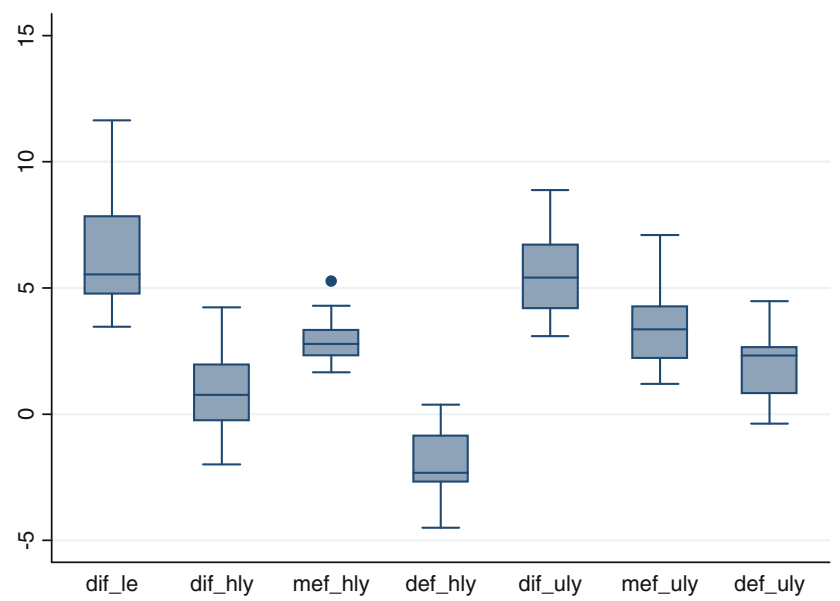

*: dif_le: gender difference (women minus men) in LE dif_hly: gender difference in HLY mef_hly: mortality effect gender difference in HLY def_hly: disability effect gender difference in HLY dif_uly: gender difference in ULY mef_uly: mortality effect gender difference in ULY def_uly: disability effect gender difference in ULY

Fig. 1 Distribution (in years) of life expectancy (le_*), healthy and unhealthy live years (hly_*, uly_*), the gender differences (female - male; dif_*) and the decomposition indicators by kind of effect (mortality (mef_*) and disability (def_*) effect) at age 15 years, EU-25, 2006

activity limitations in women reduces the gender difference in HLY. The size of these two opposing effects varies according to the country: women's disability disadvantage cancels out women's mortality advantage in seven countries so that in these countries men have a longer expectation of life without activity limitations.

Figure 2 shows the results of six different univariable meta-regression analyses. In the left column, the contribution of mortality to the gender gap in HLY is presented as a function of women's LE, men's LE and gender difference in LE. The right column presents the disability effect. When women's or men's LE is larger, the HLY gender gap is reduced mainly because women's mortality advantage is smaller but also to a lesser extent due to a larger disability disadvantage although the latter did not reach statistical significance (Table 3a). For example, a 1 -year increase in women's LE goes along with a 0.25 -year decrease of the mortality effect of the HLY gender gap (coefficient ${ }_{\text {women's LE }}:-0.25$, Table $3 \mathrm{a}$ ) while the effect of women's disability disadvantage is larger (coefficient $_{\text {women's LE }}:-0.20$, Table $3 a$ ). For every increase of 1 year in women's LE, the HLY gender gap is reduced by 0.45 years $[(-0.25)+(-0.20)]$.

The wider the gender gap in LE, the larger the gender difference in HLY due to a larger mortality women advantage (coefficient $t_{\text {LE_gender_gap: }}$ 0.30), and a smaller women's disability disadvantage (coefficient LE_gender_gap: $_{\text {: }}$ : 0.21 ). For every increase of 1 year in the gender gap in LE, the HLY gender gap increases by 0.51 years $[(0.30)+(0.21)]$. Only the mortality component of the HLY gender difference is significantly associated with the gender difference in LE and the association remains significant after adjustment for women's LE.

When the health of populations improves (measured by a higher LE, higher HLY or a lower ULY), gender differences in mortality at older ages (50 years and above) contribute more proportionally to the mortality effect of the gender difference in HLY. For instance, for every increase of 1 year in women's LE, the gender differences in the age group $50+$ years contribute almost $3 \%$ more to the mortality effect of the gender difference in HLY (coefficient $_{\text {women's LE }}$ is 2.96 , Table 4a). On the other hand, when the gender difference in either LE, HLY or ULY is large, the percentage of the mortality effect on the gender difference in HLY that can be attributed to gender differences in mortality at older ages decreases (e.g., a decrease of $3.3 \%$ for every increase of 1 year in the gender difference in LE). None of the associations of the relative contribution of older age to the disability effect on the gender difference in HLY were statistically significant.

Decomposition of the gender difference in ULY

A positive value of the ULY mortality effect indicates that women's mortality advantage results in longer life with activity limitations in women (Table 2). A positive value of 


\section{MORTALITY EFFECT}
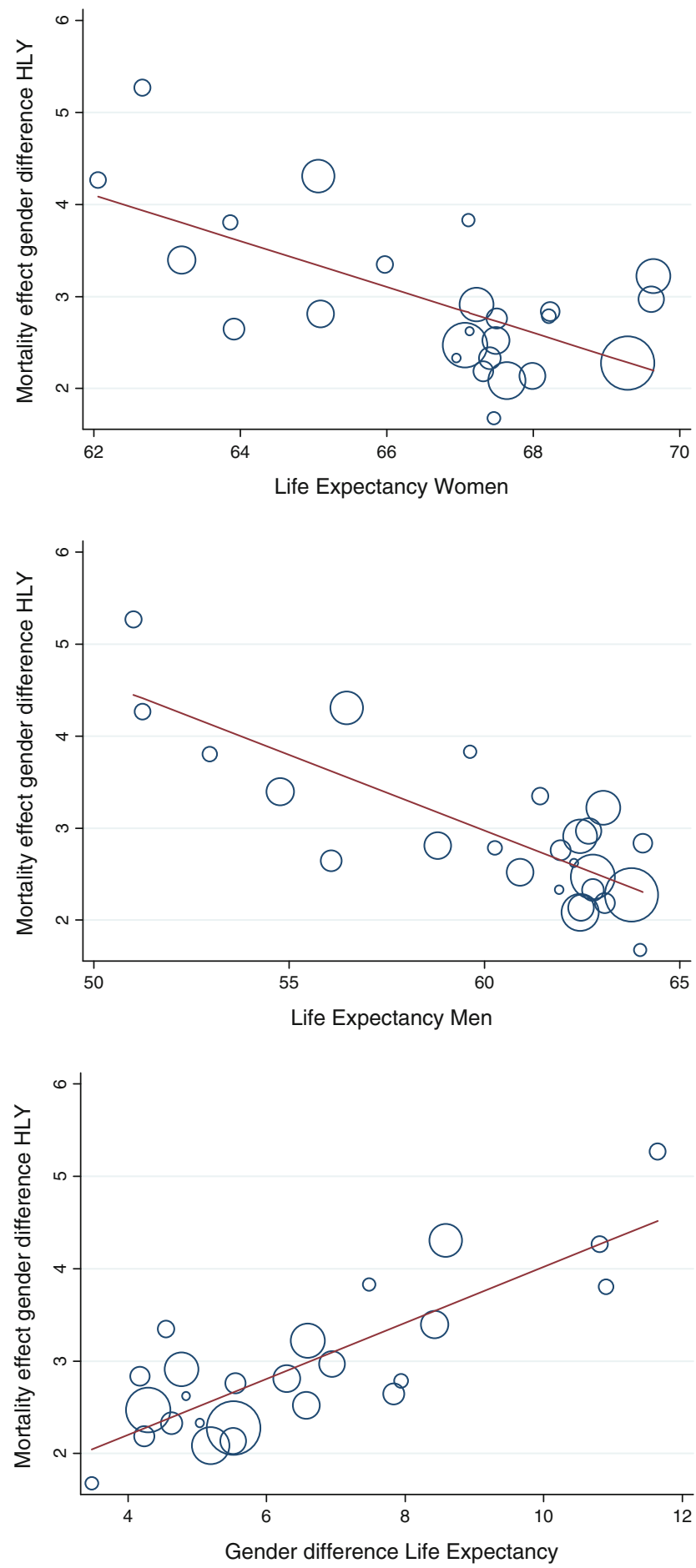

Fig. 2 Association between the life expectancy and decomposition indicators by kind of effect of the gender differences (females males) in healthy life years (HLY) at age 15 years, EU-25, 2006. Meta-regression (univariable) line graph of fitted values. Circles

the disability effect in case of the gender difference in ULY means that the higher prevalence of activity limitations in women results in a longer life of women with activity

\section{DISABILITY EFFECT}
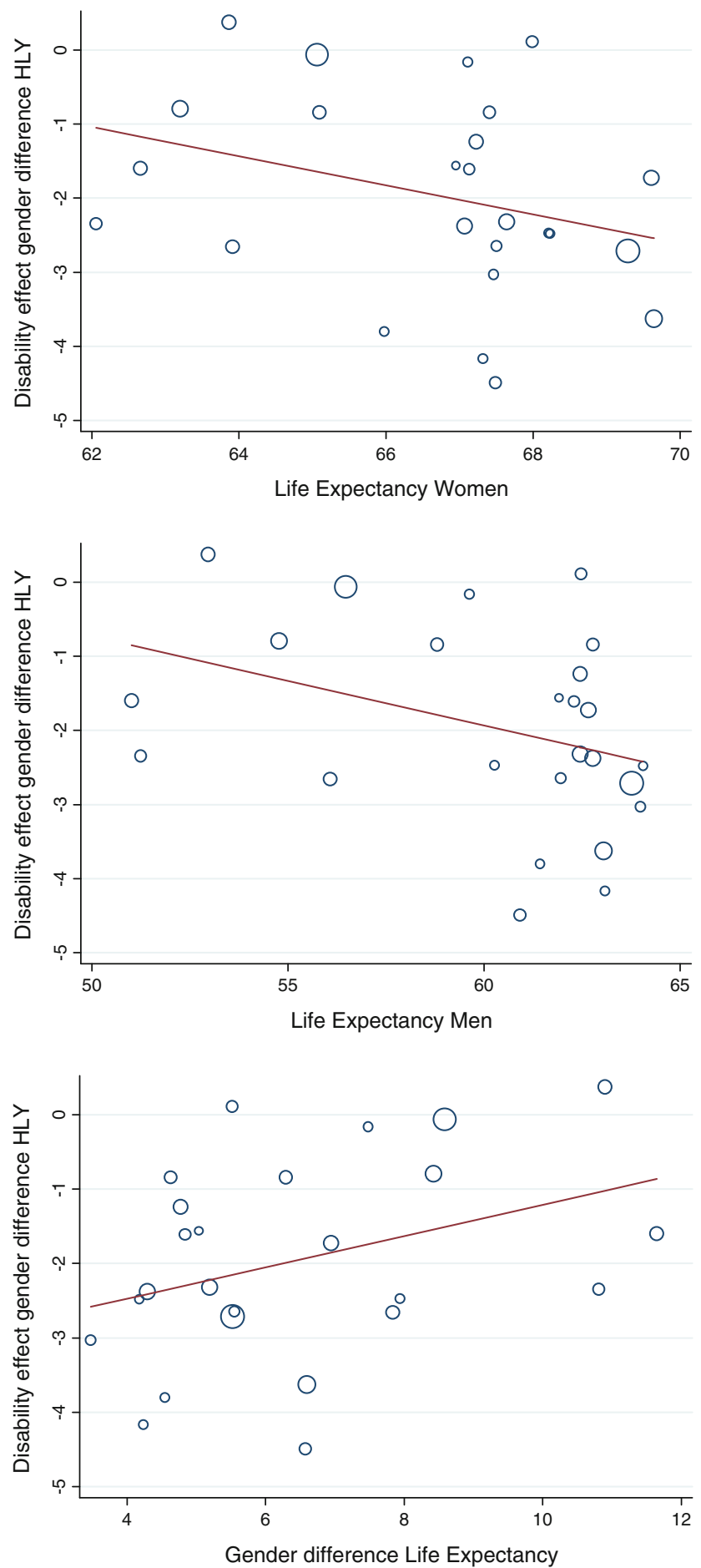

represent the estimate (mortality or disability effect) from each country, with circle size depending on the inverse of the withincountry variance

limitations. The value of the disability effect is the same for the gender gap in HLY or in ULY, but the sign is reversed. In all countries but Austria and Estonia, both the ULY mortality 


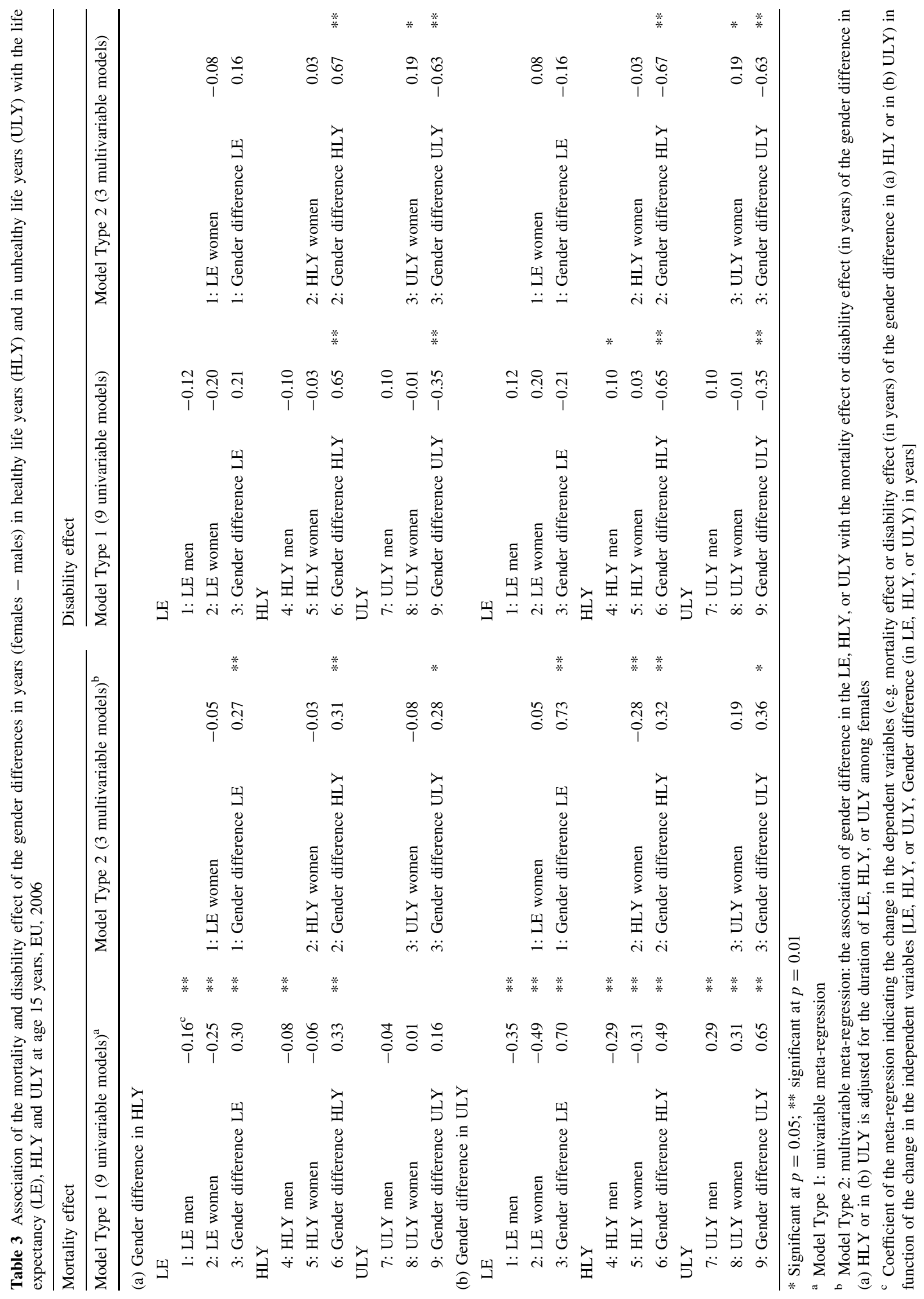




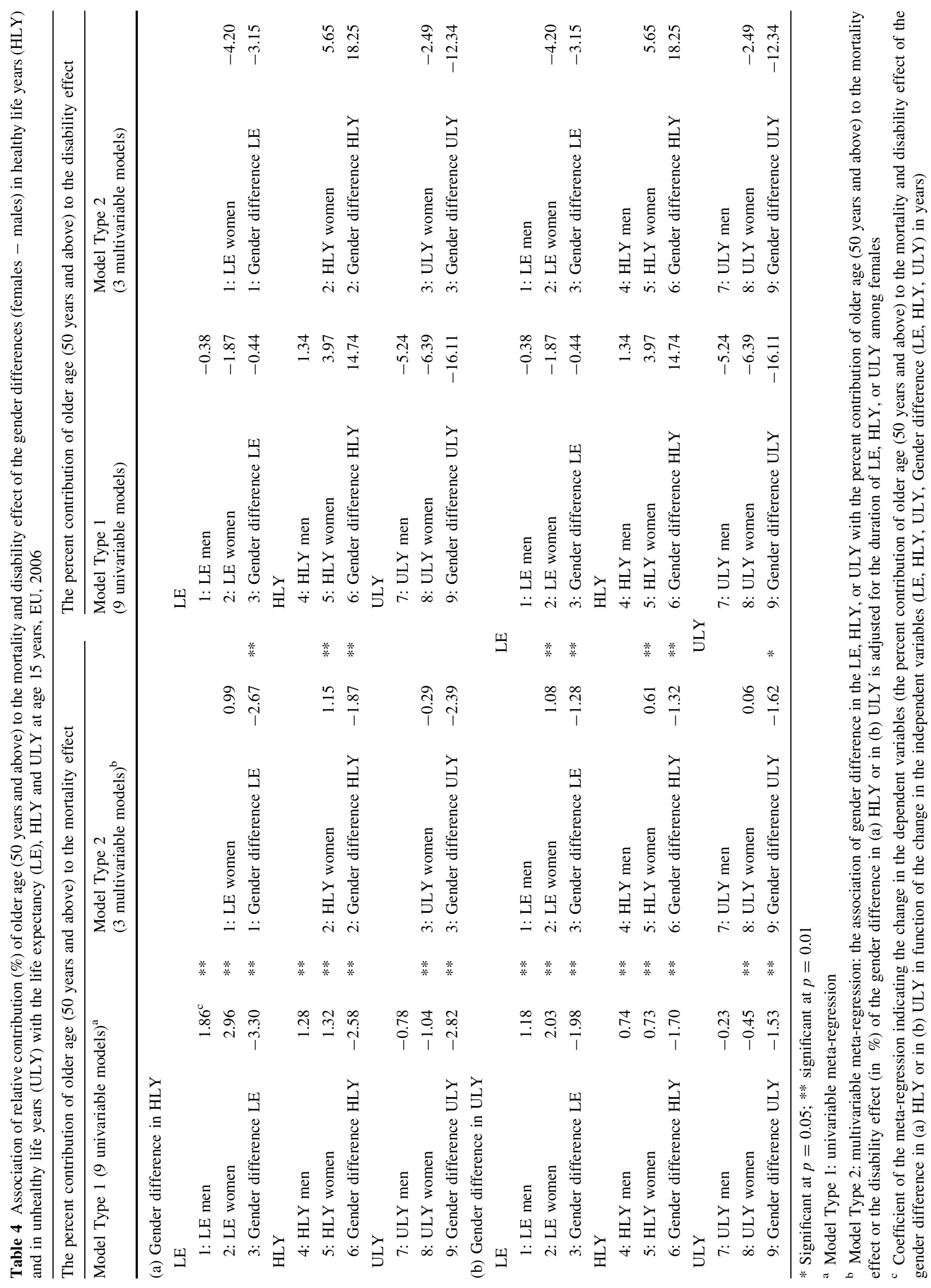


and disability effect contribute to the fact that women are living more years with activity limitations. The mortality effect is positive in all countries [median ULY mortality effect: 3.4 years (IQR 2.5, range 5.9, Fig. 1)]. In all but two countries (Austria and Estonia), women also live more years with activity limitations because they have a higher prevalence of activity limitations.

High LE in either females or males, is associated with a reduction of the gender difference in ULY mainly since women's mortality advantage is smaller [e.g., the coefficient $_{\text {women's LE }}$ is -0.49 or a 1-year increase in women's LE is associated with a decrease in the mortality effect of the gender difference in ULY by almost 0.5 years (Table 3b)]. When the gender gap in LE is wide the gender gap in ULY is large mainly because of women's larger mortality advantage (coefficient 0.70 ; Table $3 b$ ). The associations between the disability effect of the gender gaps in ULY and the LE indicators were not statistically significant. In populations with better health, there is a shift of the age groups contributing to the mortality effect of the gender difference in ULY towards older ages [coefficient $_{\text {women's LE }}$ is 2.03: the percent contribution of the age groups $50+$ years to the mortality effect of the gender difference in ULY increases with $2 \%$ when the LE in women is 1 year higher (Table 4b)]. When the gender difference in either LE, HLY or ULY is larger, a smaller part of the mortality effect on the gender difference in ULY can be attributed to difference in mortality at older ages

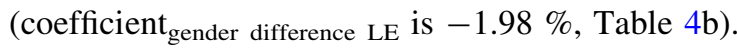

\section{Discussion}

In this paper, we approach the health-survival paradox by using composite indicators, HLY and ULY, which contain information on both components of the paradox: mortality and the prevalence of (ill)-health. Mortality and disability tend to play in opposite ways on the magnitude of the gender differentials in HLY. While women's longer life and higher disability prevalence translate into more years to be lived with disability by women, in all but two countries the disability effect compensates the mortality effect reducing the gender difference in HLY. Even more, in some countries, the disability effect overpasses the mortality effect and women live fewer years without disability. The health-survival paradox appears to be a function of the level of population health indicators and their gender difference. We observed that in populations with a high LE, the gender difference in HLY is small or even negative. Current cross-sectional analysis does not recognize that the health trajectories and the evolution of the LE during the last decades of the twentieth century were substantially different in Western European countries compared to countries of Central and Eastern Europe or the Baltic States (Leon 2011). Therefore, it is important to stress that a small or negative gender difference in HLY may mask important evolutions in the gender differences in mortality and/or activity limitations as it is a result of two opposing forces of the paradox: the survival with a smaller women's mortality advantage and the health part with a larger women's disability disadvantage. This observation is consistent with reports on trends in health expectancy indicators over time where more often evidence for compression of morbidity is reported among men alongside evidence for expansion among women (Robine et al. 2005; Van Oyen et al. 2008). The differences in evolution by gender in populations with a high LE may result from women having already reached extreme older ages and that changes in health are much more concentrated at the frontier of human life span. In populations with low life expectancy, we observed that the gender gap in HLY or ULY is large predominantly because of the large gender difference in mortality with the gender difference in the prevalence of activity limitations being less important. In populations with less favourable population health indicators such as low LE, low HLY and high ULY, the hardship among men is already evident at young ages (15-49 years), with men having higher mortality alongside a prevalence of activity limitations which is closer to that of women, yielding both an important mortality disadvantage and a lack of disability advantage relative to women. This confirms the double burden on men living in less healthy populations (countries of Central and Eastern Europe or the Baltic States) since together with their shorter life, they also have a shorter healthy life and a longer unhealthy life with a poorer health and higher mortality starting at young ages (Nusselder et al. 2010b).

Our analysis has several strengths. The country data were not pooled and the substantial heterogeneity in HLY and ULY among the EU member states is used (Jagger et al. 2008). The uncertainty around the estimates is accounted for in the meta-regression. The gender difference in HLY and ULY were subsequently separated into two parts to disentangle the health-survival paradox: one that can be explained by a differential age-specific mortality selection and the other that is due to a different agespecific prevalence of activity limitations.

Limitations of the study that should be considered are related to the cross-sectional design and the Sullivan method. The latter produces health expectancy indicators which are not period indicators and which may introduce bias in the absence of a steady state (Barendregt et al. 1994; Mathers and Robine 1997). The decomposition components do not represent the underlying processes of the incidence and recovery of activity limitations (Nusselder and Looman 2004). Further, the SILC survey is limited to 
the community dwelling population and no information is available on the health status of the institutionalized population. Not only does the proportion of the population within institutions differ between the EU countries, but the type of care-related institutions is also heterogeneous. Ignoring differences in health status between residents in the community and in institutions probably leads to an overestimation of the expected years without activity limitations. It is unknown if this bias occurs similarly in men and women in which case it would not affect gender differences. Even so, the bias may be larger in countries with a higher proportion of the population in institutions. A final limitation is related to the remaining problems in the harmonization of the GALI instrument (Van Oyen et al. 2010)

Multiple causes have been considered to explain the mechanisms which drive the health-survival paradox between the genders. The impact of methodological issues such as gender differences in survey participation or in reporting health problems have been minimized (Oksuzyan et al. 2009). Among the biological explanations most attention has been given to hormonal, autoimmune and genetic differences (Oksuzyan et al. 2008). The European LE experience during the most recent decades of last century suggests an impact of lifestyles and environmental factors including political, social and economic determinants of health, improvement of education, standards of living and health care (Leon 2011). Young men were more vulnerable to the negative health consequences of the rapid economic transition in the former communist states resulting in a high mortality of injuries, violence, cardiovascular diseases and cancers caused by high levels of alcohol consumption, especially binge drinking, smoking and poor nutrition (Mckee and Shkolnikov 2001). The lower quality of medical care in the Central and Eastern European Countries or the Baltic States may have further contributed to the more unfavourable health position of men (Newey et al. 2004). Both HLY and HLY gender gap are associated with country-specific macro-level indicators which are less favourable in countries of Central and Eastern Europe or the Baltic States (Jagger et al. 2008; Van Oyen et al. 2010). More specifically, the gender gap in HLY decreased as the gross domestic product, the expenditure on elderly care and the lifelong learning among men increased while it increased with a growing inequality in the income distribution (Van Oyen et al. 2010). Social position is an important determinant of inequality in health expectancy indictors (Bossuyt et al. 2004; Cambois et al. 2001; Crimmins and Saito 2001; Davis et al. 1999; Perenboom et al. 2005; Van Oyen et al. 2011). Women and especially older women have a lower social position as a result of a lower education or socio-economic position and this may affect the gender difference in health and functional disability (Bird and Rieker 2008). Several lifestyle factors, which have a differential uptake in men compared to women, not only affect LE, but are also associated with expected years of life without disability (Juel et al. 2008). Some of the lifestyle factors may especially influence mortality and reduce both the years lived with and without limitations; while other factors such as obesity mainly expand the years lived with disability (Reuser et al. 2009). Men have an excess of diseases which shorten life, while the disease pattern in women creates an excess in nonlethal conditions (NCHS 2009). Contributing causes of morbidity to the mortality effect of the gender difference in the disability-free life expectancy in the Netherlands were heart diseases, cancer, and COPD. Causes contributing to the disability effect of the gender difference in DFLE are heart disease, arthritis, back complaints, diabetes and COPD (Nusselder and Looman 2004). Within Europe, the wide range of gender differences in LE, HLY or ULY; the changing importance of either the mortality effect, the disability effect or the age groups contributing to the gender difference in HLY or ULY, is at the same time a statement that the health-survival paradox is not an artefact, but whatever determines the health-survival paradox is dependent on modifiable societal, social and behavioural factors.

The novelty of this paper studying the health-survival paradox is the use of HLY and the exploration of the two components of the gender difference in HLY: difference due to inequality in survival and difference due to inequality in disability. We observed large inequalities in the gender difference in health between European countries which corroborate our hypotheses. In populations with a high LE the gender difference in HLY is smaller because of the additive effect of a reduced mortality effect and a larger disability effect. In countries with a lower level of population health as indicated by a low LE, a low HLY and a large ULY, men are in the worst position having not only a higher mortality compared to women but also a high prevalence of activity limitations. Additionally, in contrast to men in populations with a better health profile, the illhealth of these men begins early in life.

Acknowledgments This work was supported by the European Public Health Programme (EHLEIS Project Grant Number 2006 109).

Open Access This article is distributed under the terms of the Creative Commons Attribution License which permits any use, distribution, and reproduction in any medium, provided the original author(s) and the source are credited.

\section{References}

Arriaga EE (1984) Measuring and explaining the change in life expectancies. Demography 21:83-96 
Austad SN (2006) Why women live longer than men: sex differences in longevity. Gend Med 3:79-92

Barendregt JJ, Bonneux L, Van der Maas PJ (1994) Health expectancy: an indicator for change? J Epidemiol Community Health 48:482-487

Barford A, Dorling D, Smith G, Shaw M (2006) Life expectancy: women now on top everywhere. BMJ 332:808

Bird CE, Rieker PP (2008) Gender and health: the effect of constrained choice and social policies. Cambridge University Press, New York

Bossuyt N, Gadeyne S, Deboosere P, Van Oyen H (2004) Socioeconomic inequalities in healthy expectancy in Belgium. Public Health 118:3-10

Cambois E, Robine JM, Hayard M (2001) Social inequality in disability-free life expectancy in the French male population, 1980-1991. Demography 38:513-524

Case A, Paxson C (2005) Sex differences in morbidity and mortality. Demography 42:189-214

Cox B, Van Oyen H, Cambois E, Jagger C, Le Roy S, Robine JM, Romieu I (2009) The reliability of the Minimum European Health Module. Int J Public Health 54:55-60

Crimmins EM, Saito Y (2001) Trends in healthy life expectancy in the United States, 1970-1990: gender, racial, and educational differences. Soc Sci Med 52:1629-1641

Davis P, Graham P, Pearce N (1999) Health expectancy in New Zealand, 1981-1991: social variations and trends in a period of rapid social and economic change. J Epidemiol Community Health 53:519-527

Efron B, Tibshirani R (1993) An introduction to the bootstrap. Chapman and Hall, New York

Eurostat (2009) Comparative final EU quality report 2006. European Commission, Luxembourg

Gjonça A, Tomassini C, Toson B, Smallwood S (2005) Sex differences in mortality. A comparison of the United Kingdom and other developed countries. Health Stat Q 26:6-16

Jacobsen R, Oksuzyan A, Engberg H, Jeune B, Vaupel J, Christensen K (2008) Sex differential in mortality trends of old-aged Danes: a nation wide study of age, period and cohort effects. Eur J Epidemiol 23:723-730

Jagger C, Cox B, Le Roy S, Clavel A, Robine JM, Romieu I, Van Oyen H (2007) Health expectancy calculation by the Sullivan method: a practical guide. EHEMU, Montpellier

Jagger C, Gillies C, Moscone F, Cambois E, Van Oyen H, Nusselder W, Robine JM (2008) Inequalities in healthy life years in the 25 countries of the European Union in 2005: a cross-national metaregression analysis. Lancet 372:2124-2131

Jagger C, Gillies C, Cambois E, Van Oyen H, Nusselder W, Robine JM (2010) The Global Activity Limitation Index measured function and disability similarly across European countries. J Clin Epidemiol 63:892-899

Juel K, Sorensen J, Bronnum-Hansen H (2008) Risk factors and public health in Denmark. Scand J Public Health 36:211-227

Leon DA (2011) Trends in European life expectancy: a salutary view. Int J Epidemiol 40:271-277

Mathers CD, Robine JM (1997) How good is Sullivan's method for monitoring changes in population health expectancies. J Epidemiol Community Health 51:80-86

McCartney G, Mahmood L, Leyland AH, Batty GD, Hunt K (2011) Contribution of smoking-related and alcohol-related deaths to the gender gap in mortality: evidence from 30 European countries. Tob Control 20:166-168

Mckee M, Shkolnikov V (2001) Understanding the toll of premature death among men in Eastern Europe. BMJ 323:1051-1055

NCHS (2009) Health, United States, 2008, with chartbook. National Center for Health Statistics, Hyattsville
Newey C, Nolte E, Mckee M, Mossialos E (2004) Avoidable mortality in the enlarged European Union. Institut des Sciences de la Sante, Paris

Nusselder WJ, Looman CWN (2004) Decomposition of differences in health expectancy by cause. Demography 41:315-334

Nusselder WJ, Looman CW, Mackenbach JP, Huisman M, Van Oyen H, Deboosere P, Gadeyne S, Kunst AE (2005) The contribution of specific diseases to educational disparities in disability-free life expectancy. Am J Public Health 95:2035-2041

Nusselder W, Jagger C, Cox B, Cambois E, Van Oyen H, Robine JM, EHLEIS Team (2010a) WP7: Decomposition tools. Technical report on decomposition. EHEMU, Montpellier

Nusselder W, Looman C, Van Oyen H, Robine JM, Jagger C (2010b) Gender differences in health of EU10 and EU15 populations: the double burden of EU10 men. Eur J Ageing 7:219-227

Oksuzyan A, Juel K, Vaupel J, Christensen K (2008) Men: good health and high mortality. Sex differences in health and aging. Aging Clin Exp Res 20:91-102

Oksuzyan A, Petersen I, Stovring H, Bingley P, Vaupel JW, Christensen K (2009) The male-female health-survival paradox: a survey and register study of the impact of sex-specific selection and information bias. Ann Epidemiol 19:504-511

Pampel FC (2003) Sex differences in mortality from lung cancer in high-income nations. Demography 40:45-65

Payne S (2004) Gender in lung cancer and smoking research. WHO, Geneva

Perenboom RJM, van Herten LM, Boshuizen HC, van den Bos GAM (2005) Life expectancy without chronic morbidity: trends in gender and socioeconomic disparities. Public Health Rep 120:46-54

Preston SH, Wang H (2006) Sex mortality differences in the United States: the role of cohort smoking patterns. Demography 43:631-646

Reuser M, Bonneux L, Willekens F (2009) Smoking kills, obesity disables: a multistate approach of the US Health and Retirement Survey. Obesity 17:783-789

Robine JM (2006) Summarizing health status. In: Pencheon D, Guest C, Melzer D, Jam G (eds) Oxford handbook of public health. Oxford University Press, Oxford, pp 160-168

Robine JM, Jagger C (2003) Creating a coherent set of indicators to monitor health across Europe: the Euro-REVES 2 project. Eur J Public Health 13:6-14

Robine JM, Romieu I, Michel JP (2003) Trends in health expectancies. In: Robine JM, Jagger C, Mathers CD, Crimmins E, Suzman R (eds) Determining health expectancies. Wiley, Chichester, pp 75-101

Robine JM, Jagger C, Van Oyen H, Cambois E, Romieu I, Clavel A, Barker G, Le Roy S (2005) Are we living longer, healthier lives in the EU? Disability-Free Life Expectancy (DFLE) in EU countries from 1991 to 2003 based on the European Household Panel. EHEMU, Montpellier

Stiefel MC, Perla RJ, Zell BL (2010) A healthy bottom line: healthy life expectancy as an outcome measure for health improvement efforts. Milbank Q 88:30-53

Sullivan DF (1971) A single index of mortality and morbidity. HSMHA Health Rep 86:347-354

Sutton AJ, Abrams KR (2001) Bayesian methods in meta-analysis and evidence synthesis. Stat Methods Med Res 10:277-303

Van Oyen H, Van der Heyden J, Perenboom R, Jagger C (2006) Monitoring population disability: evaluation of a new Global Activity Limitation Indicator (GALI). Soz Praventiv Med $51: 153-161$

Van Oyen H, Cox B, Deboosere P, Lorant V (2008) Trends in health expectancy indicators in the older adults population in Belgium between 1997 and 2004. Eur J Ageing 5:137-146 
Van Oyen H, Cox B, Jagger C, Cambois E, Nusselder W, Gilles C, Robine JM (2010) Gender gaps in life expectancy and expected years with activity limitations at age 50 in the European Union: associations with macro-level structural indicators. Eur J Ageing 7:229-237
Van Oyen H, Charafeddine R, Deboosere P, Cox B, Lorant V, Nusselder W, Demarest S (2011) Contribution of mortality and disability to the secular trend in health inequality at the turn of century in Belgium. Eur J Public Health 21:781-787 